\title{
Redo Cardiac Surgery: Bleeding Control
}

\author{
A. Seghrouchni*, M. Bamous, Y. Moutakiallah, F. Nya, N. Atmani, A. Abdou, M. Belkhadir, \\ S. Bellouize, A. Abetti, R. Mounir, A. Moujahid, A. G. Hatim, M. Drissi, Y. El Bekkali, \\ A. Boulahya, M. Ait. Houssa
}

Cardiac Surgery Department, Mohammed V Military Hospital, Mohammed V University, Rabat, Morocco

Email: *anissdr@yahoo.fr

How to cite this paper: Seghrouchni, A., Bamous, M., Moutakiallah, Y., Nya, F., Atmani, N., Abdou, A., Belkhadir, M., Bellouize, S., Abetti, A., Mounir, R., Moujahid, A., Hatim, A.G., Drissi, M., El Bekkali, Y., Boulahya, A. and Houssa, M.A. (2017) Redo Cardiac Surgery: Bleeding Control. World Journal of Cardiovascular Diseases, 7, 299-307. https://doi.org/10.4236/wjcd.2017.79028

Received: July 24, 2017

Accepted: September 22, 2017

Published: September 25, 2017

Copyright $\odot 2017$ by authors and Scientific Research Publishing Inc. This work is licensed under the Creative Commons Attribution International License (CC BY 4.0).

http://creativecommons.org/licenses/by/4.0/ (c) (i) Open Access

\begin{abstract}
Redo cardiac surgery increases mortality and morbidity. The aim of this study was to determine if aprotinin was superior to tranexamic acid concerning control bleeding loss after redo valve surgery. A retrospective study was conducted from January 1994 until December 2014. 221 patients underwent redo cardiac valve surgery and separated into two groups: aprotinin group $(\mathrm{n}=85)$ and tranexamic acid group $(\mathrm{n}=136)$. Univariate tests were applied for data analysis. A total of 221 patients were enrolled in this study. This cohort was separated into two groups: aprotinin group $(n=85)$ and tranexamic acid group $(\mathrm{n}=136)$. Euroscore in tranexamic acid group was higher: $5.96 \pm 3.04$ vs. $5.17 \pm 2.83$ in aprotinin group $(\mathrm{p}=0.055)$. There was no statistical difference in postoperative mortality between the two groups $(p=0.153)$. No statistical differences were reported concerning: total blood loss $(p=0.51)$, red blood cells transfusion $(\mathrm{p}=0.215)$, reexploration for bleeding $(\mathrm{p}=0.537)$ and postoperative renal failure $(\mathrm{p}=0.79)$. There were statistical differences concerning mechanical ventilation time, which is longer in tranexamic acid group ( $\mathrm{p}=0.008$ ) and the use of inotropic drug support, which is more frequent in the tranexamic acid group $(\mathrm{p}=0.001)$. Our results demonstrated that tranexamic acid and aprotinin reduce transfusion requirement and blood loss. Due to financial reason, we chose tranexamic acid in preventing blood loss in redo valve surgery.
\end{abstract}

\section{Keywords}

Cardiac Surgery, Aprotinin, Tranexamic Acid, Cardiopulmonary Bypass

\section{Introduction}

Redo cardiac surgery increases mortality and morbidity. Excessive perioperative bleeding is a common complication with over $50 \%$ of patients receiving blood 
product transfusions [1] [2] [3] [4].

The risk of postoperative morbidity and mortality was increased by perioperative transfusion [5]. Thus, postoperative hemorrhages affect patients' outcomes, and increase healthcare costs.

Bridges et al. found that re-exploration for control of bleeding after cardiac surgery increased four-fold mortality and sternal infection [6].

In cardiac surgery, bleeding is due to hemostasis changes by exposing blood to $\mathrm{CPB}$ circuit and also due to the surgical procedure.

In redo valve surgery, extensive surgical dissection of mediastinal and pleuro-pericardial adherences in order to mobilize the entire heart and facilitate the exposure causes diffuse capillary injuries and tissue damage that increase bleeding.

Cardiopulmonary bypass (CPB) adds major insult to the injury and creates excessive activation of the fibrinolytic system that leads to a bleeding tendency [7].

Therefore, different pharmacologic strategies have been recommended to reduce perioperative blood loss including correction of coagulopathy using tropical agents for example, spraying fibrin sealant over the pericardial surface. But the prophylactic utilization of the intra venous antifibrinolytic agents is the popular approach in preventing blood loss.

In clinical practice, aprotinin, a natural serine protease inhibitor and two lysine analogues tranexamic acid (TXA) and aminocaproic acid [8] have been used to reduce blood loss after cardiac surgery. However, there is still confusion and controversy about the best antifibrinolytic agent.

The aim of this study was to determine if aprotinin was superior to tranexamic acid concerning control bleeding loss after redo valve surgery.

\section{Methods}

After institutional ethical committee approval, database of all adult patients $(\geq 18$ years) were collected retrospectively. All patients who underwent redo cardiac surgery with cardiopulmonary bypass from January 1994 until December 2014 at our institution were included in the present retrospective observational study.

Categories in this database included patients characteristics, comorbidities, operative data, antifibrinolytic agent given, cardiopulmonary bypass time, cross clamp time, blood products transfused, 24 hours chest tube drainage and postoperative complications.

Anesthesia:

All patients were premedicated with $0.1 \mathrm{mg} / \mathrm{kg}$ of diazepam. After the transfer to the operating room the patient was given total intravenous anesthesia. This consists of sufentanil $0.5 \mathrm{mg} / \mathrm{kg}$, midazolam $3-5 \mathrm{mg} / \mathrm{kg}$, propofol $1 \mathrm{mg} / \mathrm{kg}$, vencuronium $0.6 \mathrm{mg} / \mathrm{kg}$. Antibiotic prophylaxis was given intravenously after induction of anesthesia and before skin incision closure, and continued every 6 hours during 24 hours. Cephazolin combined with aminozid were the standard choice.

Cardiopulmonary bypass:

All patients underwent redo cardiac surgery via median sternotomy. 
For anticoagulation, we administered heparin $300 \mathrm{iu} / \mathrm{kg}$ intravenously until an activated clotting time (ACT) of $>400 \mathrm{~s}$ was achieved. All CPB procedures were performed with membrane oxygenator, roller pump and under moderate hypothermia $\left(32^{\circ}-34^{\circ}\right)$.

Continuous blood flow was kept between 2.2 and $3 \mathrm{l} / \mathrm{min} / \mathrm{m}^{2}$. Myocardial protection was achieved by cold high potassium crystalloid cardioplegia solution (St Thomas) before 2000, but after this date, we routinely used cold blood cardioplegia for all patients.

Patients were weaned from $\mathrm{CPB}$ when rectal temperature was estimated $36^{\circ} \mathrm{C}$. Before giving protamine, blood from $\mathrm{CPB}$ circuit was returned back to patient. Heparin was reversed with protamin sulfate in 1:1 fashion.

Patients were divided into two groups based on the antifibrinolytic agent they were given.

The first group received aprotinin $(n=85)$. After heparinization, we infused 500,000 kiu before and after protamine administration.

The second group received tranexamic acid $(n=136)$. When heprinization was done, we injected $15 \mathrm{mg} / \mathrm{kg}$ before and after protamine administration.

We evaluated in this study: blood loss were assessed at 6 and 24 hours, hemoglobin level, platelet count and fibrinogen level. Transfusion of blood product was also evaluated.

Adverse events were predefined as follows: low cardiac output syndrome (LOS), postoperative myocardial infarction, renal failure, cerebrovascular event, reexploration due to hemorrhage and reintubation.

30 days mortality was defined as all death during 30 days after surgery.

We recorded these operation's parameters: type of intervention done, urgency of operation, operation time, CPB time, cross clamping time, time of mechanical ventilation, intensive care unit (ICU) stay, postoperative length of stay and use of inotropic drugs.

Exclusion criteria were as follows: allergy to tranexamic acid or aprotinin, preoperative coagulation defects, preoperative renal failure with hemodialysis.

Data analysis:

Statistical analysis was performed using SPSS 19.0 software (SPSS Inc., Chicago, IL, USA).

Data were represented as mean $\pm(\mathrm{SD})$ when the variables were normally distributed or as median with inter-quartile range (IQR) when the variables were not normally distributed.

T-test was used to compare normally distributed data. A non parametric test Mann-Whitney for abnormally distributed variables. A chi-square test $\mathrm{X}^{2}$ or Fisher's exact test was used to compare ordinal and categorical data respectively.

A p value of less than 0.05 was considered as statistically significant.

\section{Results}

A total of 221 patients were enrolled in this study. This cohort was divided into 
two groups: aprotinin group $(n=85)$ and TXA group $(n=136)$.

The patient demographic data are outlined in Table 1.

Patients in TXA group were more female $(75 \%$ vs. $52.9 \% \mathrm{p}=0.001)$ and were older $(45.81 \pm 10.62$ years vs. $39.86 \pm 9.25$ years $\mathrm{p}=0.0001)$ and a higher proportion of them were more symptomatic NYHA functional class III-IV: $68.3 \%$ vs. $54.1 \% \mathrm{p}=0.033$. That was explained by the delay of surgery. Duration between the first surgical procedure and the reoperation: $14.69 \pm 8$ years in TXA group vs. $12.05 \pm 5.76$ in aprotinin group $\mathrm{p}=0.005$.

Additionally, the TXA group was in higher preoperative risk score.

Euroscore: $5.96 \pm 3.04$ in TXA group vs. $5.17 \pm 2.83$ in aprotinin group $\mathrm{p}=$ 0.055 .

Concerning the rest of demographic data, there were no significant statistically differences between the two groups.

There were no differences in preoperative laboratory parameters between groups.

Preoperative hemoglobin, platelet, fibrinogen, prothrombin time, creatinine levels were similar between groups.

Table 2 shows the reasons of reoperation for patients. Although patients Table 1. Demographics of patients.

\begin{tabular}{cccc}
\hline Variable & $\begin{array}{c}\text { Group previous } \\
\text { Aprotinin }\end{array}$ & $\begin{array}{c}\text { Group re-sternotomy } \\
\text { Tranexamic acid }\end{array}$ & P value \\
\hline Age & $39.86 \pm 9.25$ & $45.81 \pm 10.62$ & 0.000 \\
Male/female & $40 / 45$ & $34 / 102$ & 0.001 \\
DM (\%) & 2.35 & 8.82 & 0.055 \\
AH (\%) & 1.17 & 5.88 & 0.158 \\
Smoking (\%) & 14.11 & 9.55 & 0.298 \\
Time (years) & $12.05 \pm 5.76$ & $14.69 \pm 8.00$ & 0.005 \\
NYHA III-IV (\%) & 54.1 & 68.3 & 0.033 \\
CTR & $0.58 \pm 0.07$ & $0.59 \pm 0.07$ & 0.374 \\
Previous stroke & 4.70 & 7.35 & 0.432 \\
Preoperative RF (\%) & 4.70 & 4.41 & 1 \\
AF & 67.05 & 71.32 & 0.502 \\
Anemia & 24.69 & 35.83 & 0.095 \\
LVEF & $59.75 \pm 10.52$ & $59.51 \pm 9.79$ & 0.869 \\
SPAP (mmHg) & $48.63 \pm 22.29$ & $51.03 \pm 17.94$ & 0.448 \\
Hemoglobin level & $13.70 \pm 2.47$ & $12.49 \pm 1.83$ & 0.000 \\
Creatinine & $9.70 \pm 2.90$ & $9.12 \pm 5.10$ & 0.438 \\
Euroscore & $5.17 \pm 2.83$ & $5.96 \pm 3.04$ & 0.055 \\
LVEF $\leq 40 \%$ & 5.88 & 5.88 & 1 \\
\hline & & & \\
\hline
\end{tabular}

DM: dibetes mellitus. AH: arteriel hypertension. NYHA: New York heart association. CTR: cardio thoracic ratio. RF: renal failure. AF: atrial fibrillation. LVEF: left ventricular ejection fraction. SPAP: systolic pulmonary arteriel pressure. 
Table 2. Cause of reoperation.

\begin{tabular}{ccc}
\hline Variable & $\begin{array}{c}\text { Group previous } \\
\text { Aprotinin } \\
(\mathbf{n}=\mathbf{8 4})\end{array}$ & $\begin{array}{c}\text { Group re-sternotomy } \\
\text { Tranexamic acid } \\
(\mathbf{n}=136)\end{array}$ \\
Thrombosis & $2(2.4 \%)$ & $3(2.2 \%)$ \\
Infective endocarditis & $5(6 \%)$ & $12(8.8 \%)$ \\
Pannus & $6(7 \%)$ & $6(4.4 \%)$ \\
Degenerescence of bioprosthesis & $4(4.8 \%)$ & $2(1.5 \%)$ \\
Reoperation for tricuspid insufficiency & $1(1.2 \%)$ & $6(4.4 \%)$ \\
Reoperation for other native valve disease & $5(6 \%)$ & $24(17.6 \%)$ \\
Association: prosthesis dysfunction + new valvulopathy & $2(2.4 \%)$ & $3(2.2 \%)$ \\
Mitral restenosis after open mitral commissurotomy & $6(7.1 \%)$ & $15(11 \%)$ \\
Mitral restenosis after CC & $34(40.5 \%)$ & $35(25.7 \%)$ \\
Reoperation after mitral plasty & $3(3.6 \%)$ & $2(1.5 \%)$ \\
False aneurysm of aorta & $0(0 \%)$ & $1(0.7 \%)$ \\
Reoperation after OMC + new valvulopathy & $16(19 \%)$ & $25(18.4 \%)$ \\
\hline
\end{tabular}

CC: closed commissurotomy. OMC: open mitral commissurotomy.

treated with aprotinin had slightly more closed mitral commissurotomy than patients treated with TXA (55.3\% vs. $41.5 \% \mathrm{p}=0.05)$, but this difference was of low clinical importance.

Other causes of redo valve surgery were similar between groups.

Intraoperatively (Table 3 ), patients receiving TXA drug had significantly longer CPB time, aortic cross clamp time, duration of surgical procedure, mechanical ventilation time. ICU stay $(p=0.0001 . p=0.0001 . p=0.0001 . p=0.005$ and $p=0.0001)$ respectively. However, the mean postoperative length of stay was similar between groups: $13.93 \pm 6.9$ days vs. $13.86 \pm 13.82$ days $(p=0.97)$.

The frequency of low cardiac output syndrome was higher in TXA group compared with aprotinin group, but it did not reach statistically significance (18.38\% vs. $9.41 \% \mathrm{p}=0.069)$. More patients in TXA group were receiving inotropic drugs compared to those treated with aprotinin: $29.41 \%$ vs. $10.58 \%(\mathrm{p}=$ 0.001). Postoperative morbidities between patients treated with tranexamic acid and those treated with aprotinin did not found significant differences (myocardial infarction, renal failure, infection neurological events).

The incidence of excessive blood loss $(>1000 \mathrm{ml} / 24 \mathrm{~h})$ was similar in both groups (aprotinin: $7.05 \%$ vs. TXA $7.35 \% \mathrm{p}=0.935$ ).

At six and 24 hours the volume of blood loss was the same between both groups. Patients treated with aprotinin required more transfusion than patient in the tranexamic group, but it didn't reach statistical significance $(45.88 \%$ vs. $37.4 \% \mathrm{p}=0.215)$.

The need for re-exploration for bleeding was slightly higher in TXA group but without clinical importance $(\mathrm{p}=0.537)$.

The mean level of hemoglobin was lower in patient receiving aprotinin at six 
Table 3. Operative Data.

\begin{tabular}{cccc}
\hline Variable & $\begin{array}{c}\text { Group previous } \\
\text { Aprotinin }\end{array}$ & $\begin{array}{c}\text { Group re-sternotomy } \\
\text { Tranexamic acid }\end{array}$ & P value \\
\hline No elective surgery (\%) & 2.35 & 6.61 & 0.211 \\
CPB time (min) & $86.80 \pm 31.36$ & $126.29 \pm 49.49$ & 0.000 \\
Cross clamp time (min) & $57.74 \pm 23.54$ & $84.34 \pm 40.47$ & 0.000 \\
Operative time (min) & $201.42 \pm 52.55$ & $241.33 \pm 69.25$ & 0.000 \\
Dissection time (min) & $66.25 \pm 31.83$ & $76.70 \pm 31.16$ & 0.028 \\
MV & $12.50(8-18)$ & $8.00(5-18)$ & 0.008 \\
MV $\geq 48$ hours (\%) & 4.81 & 14.28 & 0.028 \\
ICU & $24(22-45)$ & $48(24-72)$ & 0.000 \\
Postoperative stay & $13.86 \pm 13.82$ & $13.93 \pm 6.90$ & 0.970 \\
Lactate level & $2.77 \pm 1.07$ & $2.46 \pm 1.26$ & 0.63 \\
Blood lost H6 & $187.7 \pm 177.7$ & $156.8 \pm 112.4$ & 0.13 \\
Blood lost H20 & $440 \pm 372$ & $432.6 \pm 297$ & 0.92 \\
RBC transfusion (\%) & 45.88 & 37.40 & 0.215 \\
Reexploration for bleeding & 3.53 & 5.88 & 0.537 \\
Postoperative renal failure (\%) & 5.88 & 13.33 & 0.79 \\
Postoperative stroke (\%) & 1.17 & 1.55 & 0.148 \\
Infection (\%) & 8.23 & 14.81 & 0.069 \\
LOS (\%) & 9.41 & 18.38 & 0.153 \\
MOF (\%) & 7.05 & 29.41 & 0.001 \\
30 day mortality (\%) & 8.23 & 14.70 & \\
Inotropic support (\%) & 10.58 & & \\
\hline
\end{tabular}

CPB: cardiopulmonary bypass. MV: mechanical ventilation. ICU: intensive care unit. RBC: red blood cells. LOS: low output syndrome. MOF: multi organ failure.

hours: $10.39 \pm 1.48$ vs. $11.08 \pm 1.79(\mathrm{p}=0.004)$. But the values were similar in both groups at 24 hours: $10.48 \pm 1.56$ vs. $10.72 \pm 1.36(\mathrm{p}=0.270)$.

Postoperative platelet counts and fibrinogen level were lower in patient receiving aprotinin than those receiving tranexamic acid with statistically significance at six and 24 hours $(\mathrm{p}=0.009, \mathrm{p}=0.000)$ respectively.

Lower levels of fibrinogen were also found in aprotinin group at six and 24 hours: $\mathrm{p}=0.0001, \mathrm{p}=0.0001$ respectively.

Mortality is increased in patients treated with TXA $14.7 \%$ vs. $8.23 \%$ in patients receiving aprotinin: $\mathrm{p}=0.153$.

\section{Discussion}

Significant bleeding, especially during redo valve surgery that needs re-exploration and/or requires blood transfusion, increases morbidity and mortality [6].

Hyperfibrinolysis is one of the important contributors to excessive bleeding [9]. There is enough evidence in the cardiac surgical literature to support the beneficial effects of antifibrinolytic agents. 
In the present study, we compared the efficacy of low dose aprotinin and tranexamic acid on postoperative blood loss after redo valve surgery and need for red blood transfusion.

Tranexamic acid $(30 \mathrm{mg} / \mathrm{kg})$ associated with low dose aprotinin (500,000 kiu) on control bleeding diathesis and transfusion requirement has been studied in other studies.

In our study, both agents reduce blood loss after redo valve surgery. This finding correlates with recent meta-analysis demonstrating equivalent effects of both drugs [10] [11] [12].

Mengistu et al. [13] showed better platelet function measured by whole blood aggregation in the aprotinin group compared to tranexamic acid. In our study, patients in the aprotinin group experienced lower platelet counts than those receiving tranexamic acid either at six and 24 hours after CPB: $p=0.067 \mathrm{p}=0.009$ respectively. This finding suggested that tranexamic acid is better in prevention of platelet dysfunction than aprotinin.

In clinical practice, all agents are effective, however controversy regarding which one should be have the potential clinical superiority. Also they are not without side effects.

Use of antifibrinolytic agents must be governed by an appreciation of their inherent risks and benefits. No drug is completely safe, while patient variability also plays an important role in adverse events.

Some studies have suggested that the risk of death and renal failure is increased with the use of aprotinin than with the use of lysine analogues [14] [15] [16] [17]. These adverse events were dramatically observed in Bart study [18] and Bayer withdrawn aprotinin from the world market on May 2008.

The development of postoperative morbidities did not vary significantly between patients receiving low dose aprotinin and those receiving tranexamic acid which is consistent with finding from Van Der Linden's investigation [19]. Although aprotinin group experienced low morbidity and low mortality compared to tranexamic group, it did not reach statistical significance. However, when examining outcomes of patients treated with tranexamic acid, we found significant longer $\mathrm{CPB}$ time, longer ischemic time, prolonged mechanical support, increased proportion of LOS, all these factors might play a part in worse outcome.

In recent study, Montes [20] suggests that in the setting of renal disfunction and low output syndrome, an association between tranexamic acid use and occurrence of postoperative seizures has been demonstrated. In our study, LOS was more prevalent in tranexamic acid group but none had developed convulsive seizures.

It is known that lysine analogues are substantially cheaper than aprotinin [21]. So there are financial reasons to choose the synthetic lysine analogues, and it is routinely used alone in our patients.

Hence, the increased in hospital mortality in the tranexamic group was probably due to LOS and complications in postoperative period, which were more frequent in the aprotinin group. 
The retrospective nature of this single institution study constituted the main limitation of this paper.

This observational study did not include patients who underwent coronary artery bypass grafting, which may have introduced an additional variance when comparing results between groups. Given the small sample size of our study population, without sufficient statistical power, that makes analysis between groups difficult.

When examining the reason of redo valve surgery, we found that $40.5 \%$ of patient receiving low dose aprotinin had previously closed mitral commissurotomy (CMC) and only $26.7 \%$ in those receiving tranexamic acid. It is known the previous CMC gives less pleura-pericardic adherences than previous full sternotomy. Also, we know that large dissection of adherences in order to mobilize entire heart, increases the risk of bleeding and makes surgical procedure difficult. This parameter might be taken into account when comparing blood loss between groups.

\section{Conclusion}

Our results showed that tranexamic acid and aprotinin reduce transfusion need and blood loss. Due to financial reason, we chose tranexamic acid in preventing blood loss in redo valve surgery.

\section{References}

[1] Ferraris, V.A., Ferraris, S.P., Saha, S.P., et al. (2007) Perioperative Blood Transfusion and Blood Conservation in Cardiac Surgery: The Society of Thoracic Surgeons and the Society of Cardiovascular Anesthesiologists Clinical Practice Guideline. The Annals of Thoracic Surgery, 83, S27-S86.

[2] Levy, J.H., Ramsay, J.G. and Guyton, R.A. (2006) Aprotinin in Cardiac Surgery. The New England Journal of Medicine, 354, 1953-1957.

[3] Mehta, R.H., Sheng, S., O’Brien, S.M., Grover, F.L., Gammie, J.S., Ferguson, T.B., et al. (2009) Reoperation for Bleeding in Patients Undergoing Coronary Artery Bypass Surgery: Incidence, Risk Factors, Time Trends and Outcomes. Circulation: Cardiovascular Quality and Outcomes, 2, 583-590.

[4] Daly, D.J., Myles, P.S., Smith, J.A., Knight, J.L., Clavisi, O., Bain, D.L., et al. (2007) Anticoagulation, Bleeding and Blood Transfusion Practices in Australasian Cardiac Surgical Practice. Anaesthesia and Intensive Care, 35, 760-768.

[5] Koch, C.G., Li, L., Sessler, D.I., Figueroa, P., Hoeltge, G.A., Mihaljevic, T., et al. (2008) Duration of Red-Cell Storage and Complications after Cardiac Surgery. The New England Journal of Medicine, 358, 1229-1239.

[6] Bridges, C.R. (2007) Valid Comparisons of Antifibrinolytic Agents Used in Cardiac Surgery. Circulation, 115, 2790-2792.

[7] Larmann, J. and Theilmeier, G. (2004) Inflammatory Response to Cardiac Surgery: Cardiopulmonary Bypass versus Non-Cardiopulmonary Bypass Surgery. Best Practice \& Research Clinical Anaesthesiology, 18, 425-438. https://doi.org/10.1016/j.bpa.2003.12.004

[8] Laupacis, A. and Fergusson, D. (1977) Drugs to Minimize Perioperative Blood Loss in Cardiac Surgery: Meta-Analyses Using Perioperative Blood Transfusion as the 
Outcome. Anesthesia \& Analgesia, 85, 1258-1267.

[9] Sniecinski, R.M. and Chandler, W.L. (2011) Activation of the Hemostatic System during Cardiopulmonary Bypass. Anesthesia \& Analgesia, 113, 1319-1333.

[10] Ngaage, D.L. and Bland, J.M. (2010) Lessons from Aprotinin: Is the Routine Use and Inconsistent Dosing of Tranexamic Acid Prudent? Meta-Analysis of Randomized and Large Matched Observational Studies. European Journal of Cardio-Thoracic Surgery, 37, 1375-1383.

[11] Henry, D.A., Carless, P.A., Moxey, A.J., O’Connell, D., Stokes, B.J., Fergusson, D.A., et al. (2011) Anti-Fibrinolytic Use for Minimising Perioperative Allogeneic Blood Transfusion. The Cochrane Database of Systematic Reviews, 16, CD001886.

[12] Joseph, L. (2012) Risks of Harms using Antifibrinolytics in Cardiac Surgery: Systematic Review and Network Meta-Analysis of Randomised and Observational Studies. BMJ, 345, e5798. https://doi.org/10.1136/bmj.e5798

[13] Mengistu, A.M., Röhm, K.D., Boldt, J., Mayer, J., Suttner, S.W. and Piper, S.N. (2008) The Influence of Aprotinin and Tranexamic Acid on Platelet Function and Postoperative Blood Loss in Cardiac Surgery. Anesthesia \& Analgesia, 107, 391-397.

[14] Henry, D.A., Carless, P.A., Moxey, A.J., et al. (2007) Anti-Fibrinolytic Use for Minimising Perioperative Allogeneic Blood Transfusion. The Cochrane Database of Systematic Review, No. 3, CD001886.

[15] Brown, J.R., Birkmeyer, N.J.O. and O'Connor, G.T. (2007) Meta-Analysis Comparing the Effectiveness and Adverse Outcomes of Antifibrinolytic Agents in Cardiac Surgery. Circulation, 115, 2801-2813.

[16] Mangano, D.T., Miao, Y., Vuylsteke, A., et al. (2007) Mortality Associated with Aprotinin during 5 Years Following Coronary Artery Bypass Graft Surgery. JAMA, 297, 471-479.

[17] Shaw, A.D., Stafford-Smith, M., White, W.D., et al. (2008) The Effect of Aprotinin on Outcome after Coronary-Artery Bypass Grafting. The New England Journal of Medicine, 358, 784-793.

[18] Fergusson, D.A., Hébert, P.C., Mazer, C.D., Fremes, S., MacAdams, C., Murkin, J.M., et al. (2008) A Comparison of Aprotinin and Lysine Analogs in High-Risk Cardiac Surgery. The New England Journal of Medicine, 358, 2319-2331.

[19] Van der Linden, P.J., Hardy, J.-F., Daper, A., Trenchant, A. and De Hert, S.G. (2007) Cardiac Surgery with Cardiopulmonary Bypass: Does Aprotinin Affect Outcome? British Journal of Anaesthesia, 99, 646-652. https://doi.org/10.1093/bja/aem252

[20] Montes, F.R., Pardo, D.F., Carreño, M., Arciniegas, C., Dennis, R.J. and Umaña, J.P. (2012) Risk Factors Associated with Postoperative Seizures in Patients Undergoing Cardiac Surgery Who Received Tranexamic Acid: A Case-Control Study. Annals of Cardiac Anaesthesia, 15, 6-12. https://doi.org/10.4103/0971-9784.91467

[21] Wong, B.I., McLean, R.F., Fremes, S.E., Deemar, K.A., Harrington, E.M., Christakis, G.T. and Goldman, B.S. (2000) Aprotinin and Tranexamic Acid for High Transfusion Risk Cardiac Surgery. The Annals of Thoracic Surgery, 69, 808-816. 
Submit or recommend next manuscript to SCIRP and we will provide best service for you:

Accepting pre-submission inquiries through Email, Facebook, LinkedIn, Twitter, etc. A wide selection of journals (inclusive of 9 subjects, more than 200 journals)

Providing 24-hour high-quality service

User-friendly online submission system

Fair and swift peer-review system

Efficient typesetting and proofreading procedure

Display of the result of downloads and visits, as well as the number of cited articles Maximum dissemination of your research work

Submit your manuscript at: http://papersubmission.scirp.org/

Or contact wicd@scirp.org 